\title{
Application of Next Generation Sequencing for Diagnostic Testing of Tree Fruit Viruses and Viroids
}

M. Rott, Centre for Plant Health, Sidney Laboratory, Canadian Food Inspection Agency, North Saanich, BC, V8L 1H3, Canada; Y. Xiang, Summerland Research and Development Centre, Agriculture and Agri-Food Canada, Summerland, BC, V0H1Z0, Canada; I. Boyes, M. Belton, H. Saeed, P. Kesanakurti, S. Hayes, T. Lawrence, and C. Birch, Centre for Plant Health, Sidney Laboratory, Canadian Food Inspection Agency, North Saanich, BC, V8L 1H3, Canada; B. Bhagwat, Summerland Research and Development Centre, Agriculture and Agri-Food Canada, Summerland, BC, V0H1Z0, Canada; and H. Rast, Centre for Plant Health, Sidney Laboratory, Canadian Food Inspection Agency, North Saanich, BC, V8L 1H3, Canada

\begin{abstract}
Conventional detection of viruses and virus-like diseases of plants is accomplished using a combination of molecular, serological, and biological indexing. These are the primary tools used by plant virologists to monitor and ensure trees are free of known viral pathogens. The biological indexing assay, or bioassay, is considered to be the "gold standard" as it is the only method of the three that can detect new, uncharacterized, or poorly characterized viral disease agents. Unfortunately, this method is also the most labor intensive and can take up to three years to complete. Next generation sequencing (NGS) is a technology with rapidly expanding possibilities including potential applications for the detection of plant viruses. In this study, comparisons are made between tree fruit testing by conventional

and NGS methods, to demonstrate the efficacy of NGS. A comparison of 178 infected trees, many infected with several viral pathogens, demonstrated that conventional and NGS were equally capable of detecting known viruses and viroids. Comparable results were obtained for 170 of 178 of the specimens. Of the remaining eight specimens, some discrepancies were observed between viruses detected by the two methods, representing less than $5 \%$ of the specimens. NGS was further demonstrated to be equal or superior for the detection of new or poorly characterized viruses when compared with a conventional bioassay. These results validated both the effectiveness of conventional virus testing methods and the use of NGS as an additional or alternative method for plant virus detection.
\end{abstract}

Compared with most cellular pathogens, viruses can be difficult to detect and identify because they are obligate parasites unable to propagate outside of a host cell and are polyphyletic with no single gene shared by all viruses that could be used as a general virus test. Phytosanitary requirements for the importation of fruit trees are designed to ensure that materials entering the country are free of pathogenic viruses of concern. The list of quarantine viruses can vary depending on the status of each virus and the host crops that are grown in each individual country. In addition to known pathogenic viruses, new, potentially harmful viruses or virus strains are continuously being identified. It is important that these viruses be detected and prevented from entry before becoming established and causing potential harm. Over the years, regulatory measures have been developed and put in place to address these issues. One of the first techniques developed was biological indexing, or bioassay (for review, see Thompson et al. 2011). Material suspected of being infected with a virus is inoculated onto a sensitive indicator plant, and the indicator is observed for symptom development. Symptomology is characteristic for virus species/indicator species combinations. The process, while effective, is time consuming and labor intensive. Multiple indicator cultivars need to be inoculated and indicator plants need to be monitored at regular intervals during the growing season for up to three years. Test sites need to be isolated from commercial growing area and require restricted access. Regular mitigation procedures are required to minimize the potential movement or spread of viruses from the test site, along with ongoing care and maintenance of the plants. Highly trained personnel with specialized knowledge are needed to recognize often subtle symptoms and distinguish them from symptoms caused by other pests or environmental effects.

Corresponding author: Michael Rott, E-mail: mike.rott@inspection.gc.ca

Accepted for publication 14 April 2017.

C 2017 The American Phytopathological Society
To improve detection, additional methods have been employed, including electron microscopy to visualize virus particles (Hari and Das 1998). It wasn't until the development of polyclonal, and later monoclonal antibodies and their application in enzyme linked immunosorbant assays (ELISA) that rapid, accurate testing for known viruses became routine (López et al. 2006). Nucleic acid based test methods, most importantly polymerase chain reaction (PCR), evolved later, improving sensitivity and specificity (Hadidi et al. 1995). In today's post entry quarantine diagnostic laboratory, all of these methods are in regular use, each having unique advantages. Antibody and nucleic acid based methods are rapid and relatively inexpensive but require a priori knowledge of the virus in question. Biological indexing has the advantage of potentially detecting uncharacterized viruses for which specific molecular tests have not yet been developed, but is slow and labor intensive. Electron microscopy can also detect new viruses but is limited to characterizing gross particle morphology, is an expensive instrument to purchase and maintain, and is not effective at detecting low titer viruses or virionless viral infections.

Advances in next generation sequencing (NGS) technologies have allowed for a new metagenomic approach for the detection of viruses. Total nucleic acid extract from an infected sample corresponding to both host and pathogen(s) is sequenced and the viral sequences identified using bioinformatic tools. The rapid development of this approach has led to studies on the metagenomics analysis of virus infected plants (Coetzee et al. 2010; Jones 2014; Roossinck 2012; Roossinck et al. 2010). It is only natural that following the successful demonstration of NGS for new virus discovery, this method would eventually be applied to diagnostic testing of plant viruses. A rapid and accurate method to fully index viruses in a sample by inspection and quarantine services has been a long sought, but unattainable goal. With producer demand for access to the latest plant cultivars, there is a worldwide need for faster, more efficient methods to facilitate the movement of plants across borders while maintaining phytosanitary standards. NGS could replace many of the existing tools currently used by quarantine facilities (Martin et al. 2016). Several groups have been exploring the use of NGS for plant virus diagnostics. VirFind (Ho and Tzanetakis 2014) and VirusDetect (Zheng et al. 2017) are 
specific workflows for plant virus detection and discovery from NGS data. The Food and Environmental Research Agency in the United Kingdom are also pursuing NGS workflows for plant virus detection (Adams et al. 2009). Recently, Al Rwahnih et al. (2015) published a manuscript on "Comparison of next generation sequencing vs. biological indexing for the optimal detection of viral pathogens in grapevine" that demonstrated equal or improved detection for NGS.

NGS is potentially an ideal, universal screening method for plant virus diagnostics (Martin et al. 2016). Multiple PCR, ELISA, and bioassays could be eliminated in favor of a single NGS assay, followed up with individual confirmatory testing for a positive identification. This would greatly reduce the time, effort, and cost associated with importing foreign planting material, enabling industry to more rapidly respond to market demands for new plant cultivars developed around the world.

\section{Materials and Methods}

Specimens. Plants utilized in this study are listed in Table 1. These plants are maintained in 2 to 7 gallon pots in screen houses as controls that are used for diagnostic testing and test development at the Canadian Food Inspection Agency (CFIA), Centre for Plant Health $(\mathrm{CPH})$, Sidney Laboratory. This collection of plant specimens has been maintained and expanded since the mid-1960s (Table 1). Newly received specimens are graft inoculated onto several healthy young plants. Further propagations are made as required to replace plants that have overgrown their container or have died. Several plants corresponding to each specimen are maintained at $\mathrm{CPH}$.

Conventional testing. Conventional test methods, defined here as one or a combination of biological indexing, ELISA, and/or PCR, have been performed over time on the collection of specimens to determine disease status. Table 2 is a summary of current methods being used to detect viruses/viroids or diseases thought to be caused by a virus/viroid at $\mathrm{CPH}$. Some plants have undergone a "full range of testing" while others have been tested for only one or a few viruses/viroids. Table 2 represents a list of assays used in the past and present diagnostic program. Some of these are primary test assays; others are secondary assays used to confirm a primary test result. For example, nepoviruses are assayed initially by biological indexing and a positive result is confirmed using PCR or ELISA. While an original specimen may have been infected with multiple viruses/ viroids, some of these may not be present in subsequent propagations. As a result, discrepancies can arise between the test results. A diagnostic summary of a specimen, based on conventional testing, is the sum of the individual test results performed on the original plant and all the plants propagated from it.

dsRNA extraction and Illumina sequencing. Double stranded RNA (dsRNA) was extracted from leaf material (Kesanakurti et al. 2016) at two seasonal time points and combined, the first when the plants had just broken dormancy, and the second in late summer. This was to increase the chances of detecting viruses that may vary in titer seasonally (Roossinck 2010). Ten to $15 \mu$ l of each dsRNA extract was sent to the National Research Council, Saskatoon Laboratory for sequencing on a HiSeq 2500 (Illumina). Libraries were constructed using the TruSeq Stranded mRNA Kit (Illumina). Since the kit was designed for the construction of libraries from mRNA, the initial steps of the protocol were modified and $5 \mu l$ of dsRNA was added to $14.5 \mu \mathrm{l}$ of fragment, primer, and finish mix instead of $19.5 \mu \mathrm{l}$ as described in the original protocol. Paired-end 100 base reads were generated with 24 samples per lane. Two to 20 million reads were obtained for each sample, with the majority of samples consisting of 6 to 10 million reads.

Virus identification. Each sample was screened for viruses using Virtool (www.virtool.ca), an in-house developed sample manager that can run multiple diagnostic analysis workflows. Samples were given a unique identification number and scored for virus presence/ absence independent of the conventional test results. Paired FASTQ files imported into Virtool were trimmed using Skewer 0.2.2+ (Jiang et al. 2014) and quality assessed using FastQC $0.11 .5+$ (http://www. bioinformatics.babraham.ac.uk/projects/fastqc). A workflow, based on PathoScope (Hong et al. 2014) using Bowtie2 2.2.3+ (Langmead and Salzberg 2012) to align NGS reads to a custom database of plant virus sequences derived from GenBank, was used to screen for known viruses. PathoScope provides a framework to rapidly and accurately quantify the proportion of reads from an individual virus present in the NGS data (Hong et al. 2014). A significant advantage of using a read mapping approach compared with contig assembly is that fewer reads are required, increasing the sensitivity of the assay and minimizing the costs of sequencing (Visser et al. 2016). A virus species was considered positive for a sample if the number of matching reads was greater than 1,000 and/or coverage was greater than $15 \%$. Novel viruses were identified using the workflow NuVs in Virtool. NGS sample reads were first screened for known virus and host sequences using Bowtie 2 and discarded. Remaining reads were assembled into contigs using SPAdes 3.8+ (Bankevich et al. 2012) and viral coding regions in the contigs predicted using the vFAM resource (Skewes-Cox et al. 2014) and HMMER 3.1b2+ (Eddy 2011). Novel viral sequences were assembled into full genomes using CLCbio Genomics Workbench (Qiagen). Further analysis is in progress to determine the significance of these sequences (data not shown).

\section{Results}

Leaf samples from 178 fruit tree specimens from the $\mathrm{CPH}$, Sidney Laboratory, virus infected plant repository, were collected in May and again in September. dsRNA was extracted from each sample and the May and September extracts were combined and submitted for sequencing. NGS results for each specimen are summarized in Table 1. A variety of plant species were selected including Malus domestica, Prunus avium, P. persica, P. domestica, and Pyrus communis, with data based on conventional testing methods (ELISA, PCR, and bioassays) included for comparison. In many cases, the plants used for conventional testing were no longer available or the plant propagation available for NGS testing had been incompletely tested using conventional methods. This made a direct comparison difficult in situations where results differed between the two data sets. If a result differed, the plant used for NGS testing was retested by an independent NGS or PCR test for confirmation unless noted otherwise. Exceptions were made when the two methods differed with respect to closely related viruses, or for viruses that were not tested for by conventional methods.

Viruses and/or viroids were detected in most of the samples. In total, over 531 viral and 21 viroid sequences were identified. Both RNA and DNA viruses could be detected from the dsRNA extracts. Many of the specimens were infected with more than one virus or viroid. In at least 50 specimens, multiple genotypes were observed for one or more of the infecting viruses. For example, in sample 103, at least 12 distinct genotypes of Apple stem pitting virus (ASPV) were detected. Viruses and viroids were detected by mapping sample NGS reads to reference genomic sequences from GenBank. In most cases, thousands of reads were obtained covering 50 to $100 \%$ of the virus or viroid genome. If only a small portion of the genome was covered, for example $2 \%$, with hundreds or even thousands of reads, this could be attributed to a region in the genome of low complexity (e.g., an internal poly A region) and was not considered a positive result. A very low level of sample cross contamination was observed in the NGS data; to filter out this low level of contamination, mappings with less than 100 reads and/or less than $15 \%$ genomic coverage were considered to be negative.

Comparison of viruses/viroids/symptomology detected by conventional and NGS testing. Conventional testing identified 341 viruses/viroid/diseases, while with NGS there were 342 viruses/ viroid detections in the same 178 specimens. Of these, 313 (over $90 \%$ ) were positively identified by both methods. Results from conventional and NGS testing can be broken down into several categories: equivalent (conventional and NGS gave the same results for the virus/viroid species detected), similar (one or more virus detected by both conventional and NGS, but NGS provided a more accurate identification of the virus species, or the conventional testing was incomplete), analogous (discrepancy between conventional and NGS testing likely due to testing of different plant propagations), and 
different (one or more viruses detected by conventional or NGS not detected by the other method).

The majority of specimens, 139 or $76 \%$, gave equivalent test results from conventional and NGS methods (specimens \#1 to 139). These included Malus, Pyrus, and Prunus species infected with 19 different virus and four viroid species. No viruses or viroids were detected by either method for eight of these specimens (\#132 to 139), which were obtained as known positive controls, indicating that they were not infected with the expected virus, or that the virus had been lost during propagation. Since the results agreed between the two methods, no follow up testing was performed for these specimens.

Similar results were obtained for 22 specimens (\#140 to 161, Table 1). These could be subdivided into two groups. In the first group (\#140 to 154), both methods detected similar or closely related virus species. The improved genomic sequence resolution provided by NGS enabled a more accurate identification of the infecting virus(es) in the specimen. For example, the degenerate PCR primers, TriFoCap (Foissac et al. 2005), designed to amplify virus species from the family Betaflexiviridae, genera Trichovirus, Foveavirus, and Capillovirus, gave a positive result for \#140, \#141, and \#173. NGS detected Cherry mottle leaf virus (CMLV) in \#140 and \#141 and Cherry virus $A$ in \#173, all members of the Betaflexiviridae. Likewise, the prunus specimens (\#142 to 154) were found to be infected with one or more unclassified, but closely related, viruses of the Betaflexiviridae: Cherry green ring mottle virus (CGRMV), Cherry necrotic rusty mottle virus (CNRMV), Cherry rusty mottle virus (CRMV), Cherry twisted leaf virus (ChTLV) (Villamor et al. 2015,2016 ), or a new betaflexivirus species identified in this study (\#152 and \#153). In the second group (samples \#155 to 161), a virus or viroid was detected by NGS and not by conventional testing. In most cases, conventional testing was incomplete on these specimens leading to the discrepancy. As mentioned previously, not all plants in the repository have undergone the full range of conventional testing. For most of these specimens, the virus or viroid identified by NGS was confirmed by a second NGS and/or PCR test. For \#153 and \#158, a recently identified Prunus virus $F$ (PrVF) (Villamor et al. 2017) and geminivirus, respectively, were found by NGS. A positive bioassay result was obtained for the specimen infected with the geminivirus and a possible correlation between symptoms and the presence of this virus is ongoing. Cherry leaf roll virus (CLRV), a nepovirus, was identified in \#153 by bioassay, and could not be detected by NGS, but PrVF was found associated with this specimen by NGS. Confirmatory tests for CLRV and pathogenicity studies need to be carried out to determine if PrVF or CLRV is the etiological agent in this case.

Discrepancies were also observed for specimens \#162 to 170. However, since different plants were used for the conventional and NGS methods, the differences could be due to uneven virus distribution during plant propagation, which resulted in the observed differences. This is not unexpected since during graft inoculation, not all viruses are transferred equally from the graft infected material to the new host plant. In most cases, the propagation was retested using NGS and/or a specific PCR to confirm the presence or absence of the virus or viroid in the NGS tested propagation.

Differing results were obtained for specific viruses in \#171 to 178. For \#171 and \#172, a bioassay suggesting necrotic rusty mottle disease and prune dwarf disease symptoms, respectively, could not be confirmed in NGS and second NGS test; CVA and ChTLV were detected and confirmed by PCR. For \#173, conventional and NGS detected Asian prunus virus (APV), Plum bark necrosis stem pitting associated virus (PBNSPaV), and NGS identified CVA was also detected using the TriFoCap PCR assay. NGS also detected Tomato ringspot virus (ToRSV), which was not detected by conventional methods, but was detected using a confirmatory PCR test for ToRSV following NGS. For \#174, PBNSPaV was not detected by conventional testing, but was detected by both an initial and confirmatory NGS test. For \#175, PDV was detected by conventional PCR but could not be detected with either an initial or confirmatory NGS test. For \#176 and \#177, NGS detected a novel tymo- and a novel leuteovirus, which were not detected by conventional testing. Finally, sample \#178 was unique in that CVA was detected by NGS but not detected by conventional methods. A confirmatory PCR test to CVA was negative.

In total, 26 viruses and four viroid species were identified by NGS. Most of the viruses are single stranded RNA virus from the families Bromoviridae, Betaflexiviridae, Closteroviridae, Leutoviridae, Potyviridae, Secoviridae, and Tymoviridae, with several double stranded DNA viruses from the Caulimoviridae and Totiviridae families and a DNA virus of the Geminiviridae. Viroids from both the Pospiviroidae and Avsunviroidae families were detected.

\section{Discussion}

Conventional testing of fruits trees for virus and virus-like disease is an onerous proposition due to the various and lengthy testing procedures required. A rapid and cost effective method with equal or better sensitivity that could replace most or all conventional methods would be greatly beneficial. In this study, we were interested in comparing virus/viroid test results for infected plant specimens obtained by conventional testing to those obtained more recently by NGS. To do this, one plant per specimen was tested by NGS and the results compared with the range of conventional test procedures performed on multiple plants. It was expected that for some specimens, the results may not match for one of several possible reasons: 1) Incomplete transmission of viruses/viroids by grafting to new propagation, 2) incomplete or nonspecific virus/viroid testing by conventional methods, and 3) new virus discovery by NGS, not detectable by conventional methods. All three instances were observed, at times in combination for a particular specimen. Since it wasn't possible to validate a different result obtained from two different plants propagations if one of them was no longer available, any difference observed in this case was assumed to be due to first reason above. When results due to 1 and 2 above are eliminated from the comparison, very few differences were observed between the conventional and NGS testing. Comparable results were obtained from 170 of the 178 specimens or $96 \%$. CNRMV and PDV suspected in \#171 and \#172 based on biological indexing, which had not been confirmed using another method, tested negative by NGS. More than likely, completion of all conventional testing would have concluded neither virus was present. ToRSV (\#173) and PBNSPaV (\#174) tested negative by conventional and positive by both NGS and a confirmatory PCR test, PDV (\#175) tested positive by conventional and negative by both NGS and a confirmatory PCR test, and a novel tymovirus (\#176) and leuteovirus (\#177) positive by both NGS and confirmatory test was negative by conventional methods. These are the few instances where NGS provided a result that was distinctly different than obtained by conventional testing. The other major difference was the detection of CVA (\#178) by NGS, which could not be confirmed by PCR. For NGS, one false positive and zero false negatives were confirmed and for conventional testing, one false positive and four false negatives out of over 340 viruses/viroids were confirmed.

Based on the results, NGS can be considered a direct equivalent to conventional testing with essentially $0 \%$ false negatives. A false positive, while less serious than a false negative, is still a concern and is an issue with NGS. We suggest that for NGS to be used as a diagnostic tool, the potential for false positives be recognized, and procedures implemented to confirm positive results by a secondary method using a fresh sample extract. This is already a common practice in diagnostic testing. While we used a cut off of greater than 100 reads and/or a coverage of greater than $15 \%$ to determine a positive result by NGS, these are somewhat arbitrary numbers designed to filter out low level sample cross contamination and could be reduced with better hygienic sample handling measures throughout the NGS procedure.

For a routine testing laboratory, NGS has some clear advantages. Compared with conventional testing, it is more rapid and more samples can be processed in the same amount of time. While some of the conventional testing used for the specimens in this study can take years to complete, NGS testing and analysis can be completed in weeks or months. A single NGS sample is required, compared with 
Table 1. Conventional and NGS test results ${ }^{\mathrm{a}}$

\begin{tabular}{|c|c|c|c|c|c|c|}
\hline Specimin no. & Virus & Con & NGS & Confirm & $\mathbf{R}$ & Comments \\
\hline 1 & PDV & $\sqrt{ }$ & $\sqrt{ }$ & N/A & $\mathrm{E}$ & \\
\hline 2 & RRSV & $\sqrt{ }$ & $\sqrt{ }$ & N/A & $\mathrm{E}$ & \\
\hline 3 & RRSV, ACLSV & $\sqrt{ }$ & $\sqrt{ }$ & N/A & $\mathrm{E}$ & \\
\hline 4 & LChV-2, CVA & $\sqrt{ }$ & $\sqrt{ }$ & N/A & $\mathrm{E}$ & NGS: 2 LChV-2 and 2 CVA genotypes \\
\hline 5 & CNRMV, CVA & $\sqrt{ }$ & $\sqrt{ }$ & N/A & $\mathrm{E}$ & \\
\hline 6 & CVA, CGRMV & $\sqrt{ }$ & $\sqrt{ }$ & N/A & $\mathrm{E}$ & \\
\hline 7 & PNRSV & $\sqrt{ }$ & $\sqrt{ }$ & N/A & $\mathrm{E}$ & \\
\hline 8 & $\mathrm{LChV}-1$ & $\sqrt{ }$ & $\sqrt{ }$ & N/A & $\mathrm{E}$ & \\
\hline 9 & CVA & $\sqrt{ }$ & $\sqrt{ }$ & N/A & $\mathrm{E}$ & NGS: 3+ CVA genotypes \\
\hline 10 & PDV & $\sqrt{ }$ & $\sqrt{ }$ & N/A & $\mathrm{E}$ & \\
\hline 11 & CMLV, PDV & $\sqrt{ }$ & $\sqrt{ }$ & N/A & $\mathrm{E}$ & \\
\hline 12 & CRMV, CVA, PDV & $\sqrt{ }$ & $\sqrt{ }$ & N/A & $\mathrm{E}$ & NGS: 2 CVA genotypes \\
\hline 13 & CRMV & $\sqrt{ }$ & $\sqrt{ }$ & N/A & $\mathrm{E}$ & \\
\hline 14 & PLMVd & $\sqrt{ }$ & $\sqrt{ }$ & N/A & $\mathrm{E}$ & \\
\hline 15 & PLMVd, ACLSV & $\sqrt{ }$ & $\sqrt{ }$ & N/A & $\mathrm{E}$ & \\
\hline 16 & PLMVd & $\sqrt{ }$ & $\sqrt{ }$ & N/A & $\mathrm{E}$ & \\
\hline 17 & PNRSV & $\sqrt{ }$ & $\sqrt{ }$ & N/A & $\mathrm{E}$ & \\
\hline 18 & PNRSV & $\sqrt{ }$ & $\sqrt{ }$ & N/A & $\mathrm{E}$ & \\
\hline 19 & PLMVd & $\sqrt{ }$ & $\sqrt{ }$ & N/A & $\mathrm{E}$ & \\
\hline 20 & ACLSV & $\sqrt{ }$ & $\sqrt{ }$ & N/A & $\mathrm{E}$ & \\
\hline 21 & PLMVd, CNRMV & $\sqrt{ }$ & $\sqrt{ }$ & N/A & $\mathrm{E}$ & \\
\hline 22 & PLMVd & $\sqrt{ }$ & $\sqrt{ }$ & N/A & $\mathrm{E}$ & \\
\hline 23 & PLMVd & $\sqrt{ }$ & $\sqrt{ }$ & N/A & $\mathrm{E}$ & \\
\hline 24 & PLMVd, PcMV & $\sqrt{ }$ & $\sqrt{ }$ & N/A & $\mathrm{E}$ & \\
\hline 25 & CVA & $\sqrt{ }$ & $\sqrt{ }$ & N/A & $\mathrm{E}$ & \\
\hline 26 & PNRSV, GRMV, PDV, ACLSV, CVA & $\sqrt{ }$ & $\sqrt{ }$ & N/A & $\mathrm{E}$ & \\
\hline 27 & PDV, PNRSV & $\sqrt{ }$ & $\sqrt{ }$ & N/A & $\mathrm{E}$ & \\
\hline 28 & CGRMV, CVA, PNRSV, CMLV & $\sqrt{ }$ & $\sqrt{ }$ & N/A & $\mathrm{E}$ & NGS: 2 CVA genotypes \\
\hline 29 & ACLSV & $\sqrt{ }$ & $\sqrt{ }$ & N/A & $\mathrm{E}$ & \\
\hline 30 & PDV, PNRSV & $\sqrt{ }$ & $\sqrt{ }$ & N/A & $\mathrm{E}$ & \\
\hline 31 & CVA, CNRMV, PDV & $\sqrt{ }$ & $\sqrt{ }$ & N/A & $\mathrm{E}$ & \\
\hline 32 & PLMVd & $\sqrt{ }$ & $\sqrt{ }$ & N/A & $\mathrm{E}$ & \\
\hline 33 & PLMVd & $\sqrt{ }$ & $\sqrt{ }$ & N/A & $\mathrm{E}$ & \\
\hline 34 & PDV, PNRSV & $\sqrt{ }$ & $\sqrt{ }$ & N/A & $\mathrm{E}$ & \\
\hline 35 & PDV, PNRSV & $\sqrt{ }$ & $\sqrt{ }$ & N/A & $\mathrm{E}$ & \\
\hline 36 & APV & $\sqrt{ }$ & $\sqrt{ }$ & N/A & $\mathrm{E}$ & NGS: 2 APV genotypes \\
\hline 37 & ToRSV & $\sqrt{ }$ & $\sqrt{ }$ & N/A & $\mathrm{E}$ & \\
\hline 38 & PcMV & $\sqrt{ }$ & $\sqrt{ }$ & N/A & $\mathrm{E}$ & \\
\hline 39 & PcMV & $\sqrt{ }$ & $\sqrt{ }$ & N/A & $\mathrm{E}$ & \\
\hline 40 & PcMV & $\sqrt{ }$ & $\sqrt{ }$ & N/A & $\mathrm{E}$ & \\
\hline 41 & PcMV & $\sqrt{ }$ & $\sqrt{ }$ & N/A & $\mathrm{E}$ & \\
\hline 42 & PLMVd & $\sqrt{ }$ & $\sqrt{ }$ & N/A & $\mathrm{E}$ & \\
\hline 43 & CRMV & $\sqrt{ }$ & $\sqrt{ }$ & N/A & $\mathrm{E}$ & \\
\hline 44 & CVA, CGRMV, LCHV-2 & $\sqrt{ }$ & $\sqrt{ }$ & N/A & $\mathrm{E}$ & NGS: 2 LCHV-2 genotypes \\
\hline 45 & CVA, CGRMV & $\sqrt{ }$ & $\sqrt{ }$ & N/A & $\mathrm{E}$ & NGS: 3 CVA genotypes \\
\hline 46 & CVA, LCHV-2 & $\sqrt{ }$ & $\sqrt{ }$ & N/A & $\mathrm{E}$ & NGS: $2+$ LCHV-2 and 3 CVA genotypes \\
\hline 47 & ACLSV & $\sqrt{ }$ & $\sqrt{ }$ & N/A & $\mathrm{E}$ & \\
\hline 48 & ACLSV & $\sqrt{ }$ & $\sqrt{ }$ & N/A & $\mathrm{E}$ & NGS: multiple ACLSV genotypes \\
\hline 49 & CNRMV, CVA & $\sqrt{ }$ & $\sqrt{ }$ & N/A & $\mathrm{E}$ & \\
\hline 50 & CNRMV, PNRSV, CVA & $\sqrt{ }$ & $\sqrt{ }$ & N/A & $\mathrm{E}$ & NGS: 2 CVA and 3 PNRSV genotypes \\
\hline 51 & CVA & $\sqrt{ }$ & $\sqrt{ }$ & N/A & $\mathrm{E}$ & \\
\hline 52 & LCHV-1, ACLSV & $\sqrt{ }$ & $\sqrt{ }$ & N/A & $\mathrm{E}$ & \\
\hline 53 & CNRMV, CVA, PDV & $\sqrt{ }$ & $\sqrt{ }$ & N/A & $\mathrm{E}$ & NGS: 2 CNRMV and 3 PDV genotypes \\
\hline 54 & PNRSV, CVA & $\sqrt{ }$ & $\sqrt{ }$ & N/A & $\mathrm{E}$ & \\
\hline \multirow[t]{2}{*}{55} & CRMV, LCHV-1 & $\sqrt{ }$ & $\sqrt{ }$ & N/A & $\mathrm{E}$ & \\
\hline & & & & & & (continued on next page) \\
\hline
\end{tabular}

\footnotetext{
${ }^{\text {a }}$ Con $=$ conventional testing, NGS $=$ next generation sequencing testing, Confirm $=$ confirmatory testing of plant used for NGS testing, R $=$ result, $\sqrt{ }=$ positive test, $\mathrm{X}=$ negative test, Bio+= tested positive by bioassay, TriFoCap = positive by universal PCR assay for tricorna-, fovea-, and capilloviruses, sus = suspicious test from ELISA or PCR, NT = not tested, $\mathrm{E}=$ equivalent, $\mathrm{S}=$ similar, $\mathrm{A}=$ analogous, $\mathrm{D}=$ different. NGS(+/-) indicates that a follow up NGS test was either positive or negative, PCR(+/-) indicates that a follow up PCR test was either positive or negative, N/A = not analyzed further. If a comment refers to NGS or conventional testing, it is indicated as such. Number of identified species variants within a specimen are indicated in the Comments section. Under comparison, identical refers to specimens that tested positive by conventional and NGS methods to the same viruses. Abbreviations: American plum line pattern virus (APLPV), Apple chlorotic leaf spot virus (ACLSV), Apple dimple fruit viroid (ADFVd), Apple scar skin viroid (ASSVd), Apple stem grooving virus (ASGV), Apple stem pitting virus (ASPV), Apple mosaic virus (ApMV), Arabis mosaic virus (ArMV), Asian prunus virus 1 (APV1), Asian prunus virus 2 (APV-2), Cherry virus A (CVA), Cherry green ring mottle virus (CGRMV), Cherry mottle leaf virus (CMLV), Cherry rasp leaf virus (CRLV), Cherry necrotic rusty mottle virus (CNRMV), Cherry rusty mottle virus (CRMV), Cherry twisted leaf virus (ChTLV), Dapple apple viroid (DAVd), Hop stunt viroid (HSVd), Little cherry virus 1 (LChV-1), Little cherry virus 2 (LChV-2), Peach latent mosaic viroid (PLMVd), Peach mosaic virus (PcMV), Plum pox virus (PPV), Plum bark necrosis stem pitting associated virus (PBNSPaV), Prune dwarf virus (PDV), Prunus necrotic ringspot virus (PNRSV), Prunus virus F (PrVF), Quince yellow mosaic (QYM), Tomato blackring virus (TBRV), Tomato ringspot virus (ToRSV), Raspberry ringspot virus (RRSV).
} 
Table 1. (continued from preceding page)

\begin{tabular}{|c|c|c|c|c|c|c|}
\hline Specimin no. & Virus & Con & NGS & Confirm & $\mathbf{R}$ & Comments \\
\hline 56 & CNRMV, CVA & $\sqrt{ }$ & $\sqrt{ }$ & N/A & $\mathrm{E}$ & NGS: 2 CVA genotypes \\
\hline 57 & PNRSV, CVA, LCHV-1 & $\sqrt{ }$ & $\sqrt{ }$ & N/A & $\mathrm{E}$ & \\
\hline 58 & CMLV & $\sqrt{ }$ & $\sqrt{ }$ & N/A & $\mathrm{E}$ & \\
\hline 59 & CMLV & $\sqrt{ }$ & $\sqrt{ }$ & N/A & $\mathrm{E}$ & \\
\hline 60 & CGRMV, PDV, CVA & $\sqrt{ }$ & $\sqrt{ }$ & N/A & $\mathrm{E}$ & \\
\hline 61 & CGRMV & $\sqrt{ }$ & $\sqrt{ }$ & N/A & $\mathrm{E}$ & \\
\hline 62 & PNRSV, PDV & $\sqrt{ }$ & $\sqrt{ }$ & N/A & $\mathrm{E}$ & \\
\hline 63 & CNRMV, CVA & $\sqrt{ }$ & $\sqrt{ }$ & N/A & $\mathrm{E}$ & NGS: 2+ CVA genotypes \\
\hline 64 & LCHV-1, CVA & $\sqrt{ }$ & $\sqrt{ }$ & N/A & $\mathrm{E}$ & \\
\hline 65 & CVA & $\sqrt{ }$ & $\sqrt{ }$ & N/A & $\mathrm{E}$ & \\
\hline 66 & PPV & $\sqrt{ }$ & $\sqrt{ }$ & N/A & $\mathrm{E}$ & \\
\hline 67 & CVA & $\sqrt{ }$ & $\sqrt{ }$ & N/A & $\mathrm{E}$ & \\
\hline 68 & CVA & $\sqrt{ }$ & $\sqrt{ }$ & N/A & $\mathrm{E}$ & \\
\hline 69 & LCHV-1, CVA & $\sqrt{ }$ & $\sqrt{ }$ & N/A & $\mathrm{E}$ & NGS: 3 CVA genotypes \\
\hline 70 & PNRSV, PDV & $\sqrt{ }$ & $\sqrt{ }$ & N/A & $\mathrm{E}$ & \\
\hline 71 & $\begin{array}{l}\text { LChV-1, LChV-2, PNRSV, } \\
\text { PDV, ACLSV, CVA, CGRMV }\end{array}$ & $\sqrt{ } \sqrt{ }$ & $\sqrt{\sqrt{ }}$ & N/AN/A & $\mathrm{E}$ & $\begin{array}{l}\text { NGS: } 2 \text { LChV1 } 3 \text { PNRSV, } 3 \text { PDV and } 4 \\
\text { CVA genotypes }\end{array}$ \\
\hline 72 & ACLSV, ASPV & $\sqrt{ }$ & $\sqrt{ }$ & N/A & $\mathrm{E}$ & NGS: 2 ASPV and 2 ACLSV genotypes \\
\hline 73 & ASGV, ASPV & $\sqrt{ }$ & $\sqrt{ }$ & N/A & $\mathrm{E}$ & \\
\hline 74 & ASPV, ASGV, ACLSV & $\sqrt{ }$ & $\sqrt{ }$ & N/A & $\mathrm{E}$ & NGS: 2 ASGV and 2 ASPV genotypes \\
\hline 75 & ASPV, ACLSV & $\sqrt{ }$ & $\sqrt{ }$ & N/A & $\mathrm{E}$ & \\
\hline 76 & ASGV, ASPV, ACLSV & $\sqrt{ }$ & $\sqrt{ }$ & N/A & $\mathrm{E}$ & NGS: 9 ASPV and 2+ ACLSV genotypes \\
\hline 77 & ASPV, ACLSV & $\sqrt{ }$ & $\sqrt{ }$ & N/A & $\mathrm{E}$ & NGS: 6+ ASPV genotypes \\
\hline 78 & ACLSV & $\sqrt{ }$ & $\sqrt{ }$ & N/A & $\mathrm{E}$ & \\
\hline 79 & ACLSV & $\sqrt{ }$ & $\sqrt{ }$ & N/A & $\mathrm{E}$ & \\
\hline 80 & ASGV, ASPV, ACLSV & $\sqrt{ }$ & $\sqrt{ }$ & N/A & $\mathrm{E}$ & \\
\hline 81 & ASPV, ACLSV & $\sqrt{ }$ & $\sqrt{ }$ & N/A & $\mathrm{E}$ & $\begin{array}{l}\text { NGS: } 6+\text { ASPV and 2+ ACLSV } \\
\text { genotypes }\end{array}$ \\
\hline 82 & ACLSV, ASPV & $\sqrt{ }$ & $\sqrt{ }$ & N/A & $\mathrm{E}$ & \\
\hline 83 & ASPV, ACLSV & $\sqrt{ }$ & $\sqrt{ }$ & N/A & $\mathrm{E}$ & $\begin{array}{l}\text { NGS: 4+ ASPV and 5+ ACLSV } \\
\text { genotypes }\end{array}$ \\
\hline 84 & ASPV, ACLSV & $\sqrt{ }$ & $\sqrt{ }$ & N/A & $\mathrm{E}$ & $\begin{array}{l}\text { NGS: } 2+\text { ASPV and 2+ ACLSV } \\
\text { genotypes }\end{array}$ \\
\hline 85 & ACLSV, ASGV, ASPV, ApMV & $\sqrt{ }$ & $\sqrt{ }$ & N/A & $\mathrm{E}$ & NGS: 2+ ASPV genotypes \\
\hline 86 & ASPV, ACLSV & $\sqrt{ }$ & $\sqrt{ }$ & N/A & $\mathrm{E}$ & \\
\hline 87 & ACLSV, ASPV & $\sqrt{ }$ & $\sqrt{ }$ & N/A & $\mathrm{E}$ & NGS: 3 ACLSV and 5 ASPV genotypes \\
\hline 88 & ACLSV, ASPV & $\sqrt{ }$ & $\sqrt{ }$ & N/A & $\mathrm{E}$ & NGS: 3 ASPV genotypes \\
\hline 89 & ASPV & $\sqrt{ }$ & $\sqrt{ }$ & N/A & $\mathrm{E}$ & \\
\hline 90 & ASGV & $\sqrt{ }$ & $\sqrt{ }$ & N/A & $\mathrm{E}$ & \\
\hline 91 & ACLSV, ApMV, ASGV, ASPV & $\sqrt{ }$ & $\sqrt{ }$ & N/A & $\mathrm{E}$ & NGS: 2 ASPV genotypes \\
\hline 92 & ASGV & $\sqrt{ }$ & $\sqrt{ }$ & N/A & $\mathrm{E}$ & NGS: 2 ASGV genotypes \\
\hline 93 & ASPV, ASGV & $\sqrt{ }$ & $\sqrt{ }$ & N/A & $\mathrm{E}$ & NGS: 2 ASPV and 3 ASGV genotypes \\
\hline 94 & ASGV & $\sqrt{ }$ & $\sqrt{ }$ & N/A & $\mathrm{E}$ & NGS: 2 ASGV genotypes \\
\hline 95 & ASPV & $\sqrt{ }$ & $\sqrt{ }$ & N/A & $\mathrm{E}$ & NGS: 6 ASPV genotypes \\
\hline 96 & ACLSV & $\sqrt{ }$ & $\sqrt{ }$ & N/A & $\mathrm{E}$ & \\
\hline 97 & PPV & $\sqrt{ }$ & $\sqrt{ }$ & N/A & $\mathrm{E}$ & \\
\hline 98 & PPV & $\sqrt{ }$ & $\sqrt{ }$ & N/A & $\mathrm{E}$ & \\
\hline 99 & PPV & $\sqrt{ }$ & $\sqrt{ }$ & N/A & $\mathrm{E}$ & \\
\hline 100 & ACLSV, ASPV & $\sqrt{ }$ & $\sqrt{ }$ & N/A & $\mathrm{E}$ & NGS: 3 ACLSV and 9+ ASPV genotypes \\
\hline 101 & ACLSV & $\sqrt{ }$ & $\sqrt{ }$ & N/A & $\mathrm{E}$ & \\
\hline 102 & ASGV, ACLSV, ASPV & $\sqrt{ }$ & $\sqrt{ }$ & N/A & $\mathrm{E}$ & NGS: 2 ACLSV and 8+ ASPV genotypes \\
\hline 103 & ASGV, ACLSV, ASPV & $\sqrt{ }$ & $\sqrt{ }$ & N/A & $\mathrm{E}$ & NGS: $12+$ ASPV genotypes \\
\hline 104 & ASGV, ACLSV, ASPV & $\sqrt{ }$ & $\sqrt{ }$ & N/A & $\mathrm{E}$ & NGS: 5+ ASPV genotypes \\
\hline 105 & ACLSV, ASPV & $\sqrt{ }$ & $\sqrt{ }$ & N/A & $\mathrm{E}$ & NGS: 2 ACLSV and 8 ASPV genotypes \\
\hline 106 & ASPV & $\sqrt{ }$ & $\sqrt{ }$ & N/A & $\mathrm{E}$ & \\
\hline 107 & ASGV, ASPV & $\sqrt{ }$ & $\sqrt{ }$ & N/A & $\mathrm{E}$ & \\
\hline 108 & ASGV, ACLSV & $\sqrt{ }$ & $\sqrt{ }$ & N/A & $\mathrm{E}$ & \\
\hline 109 & ASPV & $\sqrt{ }$ & $\sqrt{ }$ & N/A & $\mathrm{E}$ & \\
\hline 110 & ASGV & $\sqrt{ }$ & $\sqrt{ }$ & N/A & $\mathrm{E}$ & \\
\hline 111 & ACLSV, ASPV & $\sqrt{ }$ & $\sqrt{ }$ & N/A & $\mathrm{E}$ & NGS: 3 ASPV genotypes \\
\hline 112 & ACLSV, ASPV & $\sqrt{ }$ & $\sqrt{ }$ & N/A & $\mathrm{E}$ & NGS: 2 ACLSV and 9 ASPV genotypes \\
\hline 113 & ACLSV & $\sqrt{ }$ & $\sqrt{ }$ & N/A & $\mathrm{E}$ & \\
\hline 114 & ADFVd & $\sqrt{ }$ & $\sqrt{ }$ & N/A & $\mathrm{E}$ & \\
\hline 115 & ADFVd & $\sqrt{ }$ & $\sqrt{ }$ & N/A & $\mathrm{E}$ & \\
\hline 116 & ACLSV, ASPV & $\sqrt{ }$ & $\sqrt{ }$ & N/A & $\mathrm{E}$ & NGS: 7 ASPV genotypes \\
\hline 117 & ALSV, ASPV, ACLSV, ASGV & $\sqrt{ }$ & $\sqrt{ }$ & N/A & E & \\
\hline 118 & ACLSV, ASPV & $\sqrt{ }$ & $\sqrt{ }$ & N/A & $\mathrm{E}$ & $\begin{array}{r}\text { NGS: } 2 \text { ACLSV and 5+ ASPV genotypes } \\
\text { (continued on next page) }\end{array}$ \\
\hline
\end{tabular}


Table 1. (continued from preceding page)

\begin{tabular}{|c|c|c|c|c|c|c|}
\hline Specimin no. & Virus & Con & NGS & Confirm & $\mathbf{R}$ & Comments \\
\hline 119 & ADFVd & $\sqrt{ }$ & $\sqrt{ }$ & N/A & $\mathrm{E}$ & \\
\hline 120 & ACLSV, ASGV, ASPV & $\sqrt{ }$ & $\sqrt{ }$ & N/A & $\mathrm{E}$ & \\
\hline 121 & ACLSV, ASPV & $\sqrt{ }$ & $\sqrt{ }$ & N/A & $\mathrm{E}$ & \\
\hline 122 & $\mathrm{AFCVd}$ & $\sqrt{ }$ & $\sqrt{ }$ & N/A & $\mathrm{E}$ & \\
\hline 123 & PBCVd & $\sqrt{ }$ & $\sqrt{ }$ & N/A & $\mathrm{E}$ & \\
\hline 124 & CNRMV, PNRSV, CVA, LCHV-1, & $\sqrt{ }$ & $\sqrt{ }$ & N/A & $\mathrm{E}$ & NGS: 2 CVA genotypes \\
\hline 125 & ACLSV, ASPV & $\sqrt{ }$ & $\sqrt{ }$ & N/A & $\mathrm{E}$ & NGS: 2 ACLSV and 7+ ASPV genotypes \\
\hline 126 & ACLSV, ASPV, ASGV, ApMV & $\sqrt{ }$ & $\sqrt{ }$ & N/A & $\mathrm{E}$ & $\begin{array}{l}\text { NGS: 4+ ACLSV and 6+ ASPV } \\
\text { genotypes }\end{array}$ \\
\hline 127 & ADFVd & $\sqrt{ }$ & $\sqrt{ }$ & N/A & $\mathrm{E}$ & \\
\hline 128 & ASPV, ASGV, ACLSV, ASSVd & $\sqrt{ }$ & $\sqrt{ }$ & N/A & E & \\
\hline 129 & $\begin{array}{l}\text { CVA, ACLSV, CGRMV, } \\
\text { PNRSV, PDV, CRLV }\end{array}$ & $\sqrt{ } \sqrt{ }$ & $\sqrt{ } \sqrt{ }$ & N/AN/A & $\mathrm{E}$ & \\
\hline 130 & PBNSPaV, APV, PLMVd, ACLSV & $\sqrt{ }$ & $\sqrt{ }$ & N/A & E & NGS: detected both APV1 and APV2 \\
\hline 131 & LChV-1, CVA & $\sqrt{ }$ & $\sqrt{ }$ & N/A & E & NGS: 2 CVA genotypes \\
\hline 132 & PLMVd & $\mathrm{X}$ & $\mathrm{X}$ & N/A & $\mathrm{E}$ & $\begin{array}{l}\text { Obtained by CPH as pos control for } \\
\text { PLMVd }\end{array}$ \\
\hline 133 & PDV & $\mathrm{X}$ & $\mathrm{X}$ & N/A & $\mathrm{E}$ & Obtained by $\mathrm{CPH}$ as pos control for PDV \\
\hline 134 & QYM & $\mathrm{X}$ & $\mathrm{X}$ & N/A & E & Obtained by $\mathrm{CPH}$ as pos control for QYM \\
\hline 135 & QYM & $\mathrm{X}$ & $\mathrm{X}$ & N/A & $\mathrm{E}$ & Obtained by $\mathrm{CPH}$ as pos control for QYM \\
\hline 136 & QYM & $\mathrm{X}$ & $\mathrm{X}$ & N/A & $\mathrm{E}$ & Obtained by $\mathrm{CPH}$ as pos control for QYM \\
\hline 137 & QYM & $\mathrm{X}$ & $\mathrm{X}$ & N/A & $\mathrm{E}$ & Obtained by $\mathrm{CPH}$ as pos control for QYM \\
\hline 138 & PDV, CLRV & $\mathrm{X}$ & $\mathrm{X}$ & N/A & $\mathrm{E}$ & $\begin{array}{l}\text { Obtained by CPH as pos control for PDV } \\
\text { and CLRV }\end{array}$ \\
\hline 139 & ACLSV & $\mathrm{X}$ & $\mathrm{X}$ & N/A & $\mathrm{E}$ & $\begin{array}{l}\text { Obtained by CPH as a positive control for } \\
\text { ACLSV }\end{array}$ \\
\hline 140 & CMLV & TriFoCap & $\sqrt{ }$ & N/A & S & $\begin{array}{l}\text { Conventional: TriFoCap primers are } \\
\text { positive for CMLV }\end{array}$ \\
\hline 141 & CMLV & TriFoCap & $\sqrt{ }$ & N/A & S & $\begin{array}{l}\text { Conventional: TriFoCap primers are } \\
\text { positive for CMLV }\end{array}$ \\
\hline 142 & CRMVCNRMV, ChTLV & $\mathrm{Bio}+\mathrm{Bio}+$ & $\sqrt{ }$ & N/A & S & $\begin{array}{l}\text { Conventional: ChTLV/CRMV/CNRMV } \\
\text { can cross react }\end{array}$ \\
\hline 143 & $\begin{array}{l}\text { CMLV, PDV, CGRMV } \\
\text { CRMV }\end{array}$ & $\begin{array}{c}\sqrt{ } \\
\text { Bio+ }\end{array}$ & $\begin{array}{l}X \\
\sqrt{ } \\
X\end{array}$ & N/A & S & $\begin{array}{l}\text { NGS: more accurate species identification } \\
\text { Conventional: Suspicious symptoms from } \\
\text { bioassay, CRMV/CGRMV can cross } \\
\text { react }\end{array}$ \\
\hline \multirow[t]{3}{*}{144} & CRMV & $\sqrt{ }$ & $\sqrt{ }$ & N/A & S & $\begin{array}{l}\text { Conventional: CHTLV/CRMV/CNRMV } \\
\text { can cross react }\end{array}$ \\
\hline & CNRMV & $\sqrt{ }$ & $\mathrm{X}$ & & & NGS: more accurate species identification \\
\hline & ChTLV & Bio+ & $\mathrm{X}$ & & & \\
\hline \multirow[t]{2}{*}{145} & CVA, CGRMV & $\sqrt{ }$ & $\sqrt{ }$ & N/A & S & $\begin{array}{l}\text { Conventional: CNRMV/CGRMV can } \\
\text { cross react }\end{array}$ \\
\hline & CNRMV & sus & $\mathrm{X}$ & & & NGS: more accurate species identification \\
\hline \multirow[t]{2}{*}{146} & CNRMV & $\sqrt{ }$ & $\mathrm{X}$ & N/A & S & $\begin{array}{l}\text { Conventional: CNRMV/CRMV can cross } \\
\text { react }\end{array}$ \\
\hline & CRMV & $\mathrm{X}$ & $\sqrt{ }$ & & & $\begin{array}{l}\text { NGS: more accurate identification of } \\
\text { CRMV }\end{array}$ \\
\hline \multirow[t]{3}{*}{147} & CVA & $\sqrt{ }$ & $\sqrt{ }$ & N/A & S & $\begin{array}{l}\text { Conventional: CGRMV/CNRMV/ } \\
\text { CRMV can cross react }\end{array}$ \\
\hline & CGRMV, CMLV, CNRMV & $\sqrt{ }$ & $\mathrm{X}$ & & & NGS: more accurate species identification \\
\hline & CRMV & $\mathrm{X}$ & $\sqrt{ }$ & & & NGS: 5 CVA genotypes \\
\hline 148 & $\begin{array}{l}\text { PDV, CVA, CNRMV, ACLSV } \\
\text { CGRMV }\end{array}$ & $\sqrt{ }$ & $\begin{array}{l}\sqrt{ } \\
X\end{array}$ & N/A & $\mathrm{S}$ & $\begin{array}{l}\text { NGS: } 3 \text { CVA genotypes } \\
\text { Conventional: CNRMV/CGRMV can } \\
\text { cross react }\end{array}$ \\
\hline 149 & $\begin{array}{l}\text { PNRSV, CGRMV, ACLSV, LChV-1 } \\
\text { CNRMV }\end{array}$ & $\begin{array}{l}\sqrt{ } \\
X\end{array}$ & $\sqrt{ }$ & N/A & S & $\begin{array}{l}\text { Conventional: CGRMV/CNRMV can } \\
\text { cross react }\end{array}$ \\
\hline 150 & $\begin{array}{l}\text { CGRMV, PDV, PNRSV, CVA, CMLV } \\
\text { CNRMV }\end{array}$ & $\begin{array}{l}\sqrt{ } \\
X\end{array}$ & $\sqrt{ }$ & N/A & S & $\begin{array}{l}\text { Conventional: CGRMV/CNRMV can } \\
\text { cross react }\end{array}$ \\
\hline \multirow[t]{2}{*}{151} & $\begin{array}{l}\text { CVA, ACLSV, LChV-1 } \\
\text { CRMV }\end{array}$ & $\sqrt{ }$ & 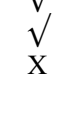 & N/A & S & $\begin{array}{l}\text { NGS: } 2 \text { ACLSV genotypes } \\
\text { Conventional: CRMV related to new } \\
\text { betaflexivirus and could cross react }\end{array}$ \\
\hline & novel betaflexivirus & $\mathrm{X}$ & $\sqrt{ }$ & & & \\
\hline \multirow[t]{3}{*}{152} & CVA, ACLSV, LCHV-1 & $\sqrt{ }$ & $\sqrt{ }$ & N/A & S & NGS: 2 ACLSV genotypes \\
\hline & CRMV & $\sqrt{ }$ & $\mathrm{X}$ & & & $\begin{array}{l}\text { Conventional: CRMV related to new } \\
\text { betaflexivirus and could cross react }\end{array}$ \\
\hline & novel betaflexivirus & $\mathrm{X}$ & $\sqrt{ }$ & & & \\
\hline \multirow[t]{2}{*}{153} & PDV, CVA & $\sqrt{ }$ & $\sqrt{ }$ & N/A & S & NGS: 2 CVA genotypes \\
\hline & CLRV & Bio+ & $\mathrm{X}$ & & & $\begin{array}{r}\text { PrVF and CLRV members of Secoviridae } \\
\text { (continued on next page) }\end{array}$ \\
\hline
\end{tabular}


Table 1. (continued from preceding page)

\begin{tabular}{|c|c|c|c|c|c|c|}
\hline Specimin no. & Virus & Con & NGS & Confirm & $\mathbf{R}$ & Comments \\
\hline & PrVF & NT & $\sqrt{ }$ & & & \\
\hline \multirow[t]{4}{*}{154} & CGRMV & $\sqrt{ }$ & $\sqrt{ }$ & & $\mathrm{S}$ & NGS: 3+ CNRMV genotypes \\
\hline & CMLV & $\sqrt{ }$ & $\sqrt{ }$ & & & $\begin{array}{l}\text { Conventional: CGRMV and CNRMV } \\
\text { can cross react }\end{array}$ \\
\hline & CNRMV & NT & $\sqrt{ }$ & & & $\begin{array}{l}\text { Propagation tested by NGS was not } \\
\text { initially tested for CNRMV by } \\
\text { conventional methods. }\end{array}$ \\
\hline & CVA & NT & $\sqrt{ }$ & & & \\
\hline \multirow[t]{2}{*}{155} & CMLV & $\sqrt{ }$ & $\sqrt{ }$ & N/A & $\mathrm{S}$ & Conventional: not initially tested for \\
\hline & PLMVd & NT & $\sqrt{ }$ & & & PLMVd \\
\hline \multirow[t]{2}{*}{156} & PcMV & $\sqrt{ }$ & $\sqrt{ }$ & & $\mathrm{S}$ & Conventional: not initially tested for \\
\hline & ACLSV & NT & $\sqrt{ }$ & $\operatorname{PCR}(+)$ & & ACLSV \\
\hline \multirow[t]{2}{*}{157} & LChV-2 & $\sqrt{ }$ & $\sqrt{ }$ & N/A & $\mathrm{S}$ & Conventional: not initially tested for \\
\hline & PLMVd & NT & $\sqrt{ }$ & & & PLMVd \\
\hline \multirow[t]{2}{*}{158} & CVA & NT & $\sqrt{ }$ & PCR, NGS(+) & $\mathrm{S}$ & Conventional: not initially tested for CVA \\
\hline & novel geminivirus & Bio+ & $\sqrt{ }$ & NGS(+) & & \\
\hline \multirow[t]{2}{*}{159} & PPV, CVA & $\sqrt{ }$ & $\sqrt{ }$ & NGS (+) & $\mathrm{S}$ & Conventional: not initially tested for \\
\hline & LCHV-1 & NT & $\sqrt{ }$ & $\mathrm{NGS}(+)$ & & LChV-1 \\
\hline \multirow[t]{2}{*}{160} & CGRMV, CVA, PNRSV, CNRMV & $\sqrt{ }$ & $\sqrt{ }$ & & $\mathrm{S}$ & Conventional: not initially tested for PDV \\
\hline & PDV & NT & $\sqrt{ }$ & $\mathrm{PCR}(+\mathrm{PDV})$ & & \\
\hline 161 & LChV-1 & NT & $\sqrt{ }$ & NGS(+) & $\mathrm{S}$ & $\begin{array}{l}\text { Conventional: not initially tested for } \\
\text { LChV-1 }\end{array}$ \\
\hline \multirow[t]{3}{*}{162} & CVA, LChV-2, APLPV & $\sqrt{ }$ & $\sqrt{ }$ & NGS(+) & A & $\begin{array}{l}\text { Conventional: not initially tested for } \\
\text { LChV-1 }\end{array}$ \\
\hline & LChV-1 & NT & $\sqrt{ }$ & NGS(+) & & $\begin{array}{l}\text { Different propagations tested by } \\
\text { conventional versus NGS }\end{array}$ \\
\hline & CNRMV & Bio+ & $\mathrm{X}$ & NGS, PCR (-) & & \\
\hline \multirow[t]{2}{*}{163} & TBRV & sus & $\mathrm{X}$ & NGS (-) & A & $\begin{array}{l}\text { Propagation tested by NGS was not } \\
\text { initially tested for PLMVd. }\end{array}$ \\
\hline & PLMVd & NT & $\sqrt{ }$ & $\mathrm{NGS}(+)$ & & $\begin{array}{l}\text { Different propagations tested by } \\
\text { conventional versus NGS }\end{array}$ \\
\hline \multirow[t]{2}{*}{164} & PPV & $\sqrt{ }$ & $\sqrt{ }$ & N/A & A & Different propagations tested by \\
\hline & PLMVd & $\sqrt{ }$ & $\mathrm{X}$ & N/A & & conventional versus NGS \\
\hline \multirow[t]{2}{*}{165} & CRMV & Bio+ & $\mathrm{X}$ & NGS(-) & A & Different propagations tested by \\
\hline & CVA & $\sqrt{ }$ & $\mathrm{X}$ & NGS(-) & & conventional versus NGS \\
\hline 166 & PLMVd & $\sqrt{ }$ & $\mathrm{X}$ & N/A & A & $\begin{array}{l}\text { Different propagations tested by } \\
\text { conventional versus NGS }\end{array}$ \\
\hline 167 & CVA, CGRMV & $\sqrt{ }$ & $\mathrm{X}$ & PCR(-CVA) NGS(-all) & A & $\begin{array}{l}\text { Different propagations tested by } \\
\text { conventional versus NGS }\end{array}$ \\
\hline 168 & PNRSV, PLMVd & $\sqrt{ }$ & $\mathrm{X}$ & NGS(-) & A & $\begin{array}{l}\text { Different propagations tested by } \\
\text { conventional versus NGS }\end{array}$ \\
\hline \multirow[t]{2}{*}{169} & ACLSV & $\sqrt{ }$ & $\sqrt{ }$ & & A & Different propagations tested by \\
\hline & ASPV & $\sqrt{ }$ & $\mathrm{X}$ & PCR(-) & & conventional versus NGS \\
\hline \multirow[t]{2}{*}{170} & ASGV & $\sqrt{ }$ & $\sqrt{ }$ & $\mathrm{NGS}(+)$ & A & Different propagations tested by \\
\hline & ACLSV & $\sqrt{ }$ & $\mathrm{X}$ & NGS(-) & & conventional versus d NGS \\
\hline \multirow[t]{2}{*}{171} & CVA & $\sqrt{ }$ & $\sqrt{ }$ & $\mathrm{NGS}(+)$ & $\mathrm{D}$ & NGS: multiple CVA genotypes \\
\hline & CNRMV & $\mathrm{Bio}+$ & $\mathrm{X}$ & NGS(-) & & $\begin{array}{l}\text { Conventional: Suspicious symptoms } \\
\text { from bioassay }\end{array}$ \\
\hline \multirow[t]{2}{*}{172} & ChTLV & $\sqrt{ }$ & $\sqrt{ }$ & $\mathrm{NGS}(+)$ & $\mathrm{D}$ & $\begin{array}{l}\text { Conventional: CNRMV/CGRMV can } \\
\text { cross react }\end{array}$ \\
\hline & PDV, CNRMV & $\mathrm{Bio}+$ & $\mathrm{X}$ & NGS(-) & & $\begin{array}{l}\text { Conventional: Suspicious symptoms from } \\
\text { bioassay }\end{array}$ \\
\hline \multirow[t]{4}{*}{173} & APV & $\sqrt{ }$ & $\sqrt{ }$ & & $\mathrm{D}$ & $\begin{array}{l}\text { Propagation tested by NGS was not } \\
\text { initially tested for CVA }\end{array}$ \\
\hline & PBNSPaV & sus & $\sqrt{ }$ & & & \\
\hline & CVA & TriFoCap & $\sqrt{ }$ & & & \\
\hline & ToRSV & $\mathrm{X}^{1}$ & $\sqrt{ }$ & & & \\
\hline \multirow[t]{2}{*}{174} & ACLSV, CGRMV, CNRMV & $\sqrt{ }$ & $\sqrt{ }$ & $\mathrm{NGS}(+)$ & $\mathrm{D}$ & NGS: 2 PBNSPaV genotypes \\
\hline & PBNSPaV & $\mathrm{X}$ & $\sqrt{ }$ & NGS(+) & & \\
\hline \multirow[t]{2}{*}{175} & LCHV-2, CVA, ACLSV & $\sqrt{ }$ & $\sqrt{ }$ & $\mathrm{NGS}(+)$ & $\mathrm{D}$ & NGS: 3 CVA genotypes \\
\hline & PDV & $\sqrt{ }$ & $\mathrm{X}$ & NGS(-) & & \\
\hline 176 & CNRMV, PPV & $\sqrt{ }$ & $\sqrt{ }$ & $\mathrm{NGS}(+)$ & $\mathrm{D}$ & \\
\hline & novel tymovirus & $\mathrm{X}$ & $\sqrt{ }$ & $\mathrm{NGS}(+)$ & & \\
\hline 177 & PLMVd & $\sqrt{ }$ & $\sqrt{ }$ & $\mathrm{NGS}(+)$ & $\mathrm{D}$ & Conventional: not initially tested for \\
\hline & TBRV & NT & $\sqrt{ }$ & $\mathrm{NGS}(+)$ & & TBRV \\
\hline & novel leuteovirus & $\mathrm{X}$ & $\sqrt{ }$ & $\mathrm{NGS}(+)$ & & \\
\hline 178 & PPV & $\sqrt{ }$ & $\sqrt{ }$ & & $\mathrm{D}$ & Conventional: not initially tested for \\
\hline & PNRSV, LChV-1, ACLSV & NT & $\sqrt{ }$ & $\operatorname{PCR}(+)$ & & PNRSV, CVA, LChV-1 or ACLSV \\
\hline & CVA & NT & $\sqrt{ }$ & PCR(-) & & \\
\hline
\end{tabular}


Table 2. Test methods used for viruses, viroids, and suspected virus diseases of Malus, Prunus, and Pyrus

\begin{tabular}{|c|c|c|c|c|c|}
\hline \multirow[b]{2}{*}{ Virus species/disease } & \multirow[b]{2}{*}{ Host } & \multicolumn{4}{|c|}{ Test method } \\
\hline & & ELISA & PCR & Woody bioassay $^{a}$ & Herbaceous bioassay $^{a}$ \\
\hline American plum line pattern virus & Prunus & & & Shiro plum & C. sativus \\
\hline Apple chat fruit & Malus & & & Lord Lambourne & \\
\hline \multirow[t]{5}{*}{ Apple chlorotic leafspot virus } & Malus & $\mathrm{X}^{\mathrm{b}}$ & $\mathrm{X}^{\mathrm{c}}$ & R $127407 \mathrm{~A}$ & C. amaranticolor \\
\hline & Prunus & $\mathrm{X}^{\mathrm{b}}$ & $\mathrm{X}^{\mathrm{c}}$ & Spy 227 & N. occidentalis $37 B$ \\
\hline & Pyrus & $\mathrm{X}^{\mathrm{b}}$ & $\mathrm{X}^{\mathrm{c}}$ & GF 305 & N. occidentalis obliqua \\
\hline & & & & P. tomentosa & C. quinoa \\
\hline & & & & P. veitchii & \\
\hline Apple dimple fruit viroid & Malus & & $X^{d}$ & & \\
\hline Apple fruit crinkle viroid & Malus & & $\mathrm{X}^{\mathrm{e}}$ & & \\
\hline \multirow[t]{3}{*}{ Apple green crinkle viroid } & Malus & & $X^{f}$ & Cox's Orange Pippin & \\
\hline & & & & Golden Delicious & \\
\hline & & & & Granny Smith & \\
\hline \multirow[t]{2}{*}{ Apple leaf pucker } & Malus & & & Golden Delicious & \\
\hline & & & & Spartan & \\
\hline Apple latent spherical virus & Malus & & $X^{g}$ & & C. quinoa \\
\hline \multirow[t]{3}{*}{ Apple mosaic virus } & Malus & $\mathrm{X}^{\mathrm{h}}$ & $\mathrm{X}^{\mathrm{c}}$ & Golden Delicious & \\
\hline & Prunus & $\mathrm{X}^{\mathrm{h}}$ & $\mathrm{X}^{\mathrm{c}}$ & Lord Lambourne & \\
\hline & & & & GF 305 & \\
\hline Apple rasp leaf & Malus & & & Golden Delicious & \\
\hline \multirow[t]{3}{*}{ Apple ringspot } & Malus & & & Cox's Orange Pippin & \\
\hline & & & & Golden Delicious & \\
\hline & & & & Granny Smith & \\
\hline Apple rough skin & Malus & & & Golden Delicious & \\
\hline \multirow[t]{2}{*}{ Apple rubbery wood } & Malus & & & Lord Lambourne & \\
\hline & Pyrus & & & Lord Lambourne & \\
\hline \multirow[t]{3}{*}{ Apple scar skin viroid } & Malus & & $X^{d}$ & Lord Lambourne & \\
\hline & Pyrus & & $X^{d}$ & Spartan & \\
\hline & & & & Lord Lambourne & \\
\hline \multirow[t]{4}{*}{ Apple stem grooving virus } & Malus & & $X^{c, i}$ & Virginia Crab & C. amaranticolor \\
\hline & Pyrus & & $X^{c, i}$ & P. veitchii & N. occidentalis $37 B$ \\
\hline & & & & Virginia Crab & N. occidentalis obliqua \\
\hline & & & & & C. quinoa \\
\hline \multirow[t]{5}{*}{ Apple stem pitting virus } & Malus & & $\mathrm{X}^{\mathrm{c}}$ & Spy 227 & N. occidentalis $37 B$ \\
\hline & Pyrus & & & Virginia Crab & N. occidentalis obliqua \\
\hline & & & & Jules D'Airolles & \\
\hline & & & & P. veitchii & \\
\hline & & & & Virginia Crab & \\
\hline Apricot latent virus & Prunus & & $X^{i, j}$ & & \\
\hline Apricot leaf pucker & Prunus & & & Tilton & \\
\hline \multirow[t]{3}{*}{ Arabis mosaic virus } & Malus & $\mathrm{X}^{\mathrm{b}}$ & $\mathrm{X}$ & & C. amaranticolor \\
\hline & Pyrus & $\mathrm{X}$ & $\mathrm{X}$ & GF 305 & C. quinoa \\
\hline & Prunus & $\mathrm{X}^{\mathrm{b}}$ & & Bing & N. benthamiana \\
\hline Asian prunus virus & Prunus & & $X^{i, k}$ & & \\
\hline Bark split & Pyrus & & & Bartlett & \\
\hline \multirow[t]{2}{*}{ Cherry albino } & Prunus & & & Lambert & \\
\hline & & & & & (continued on next page) \\
\hline
\end{tabular}

a Thompson et al. 2011. Pages 299-302 in Virus and Virus-Like Diseases of Pome and Stone Fruits, APS Press, St. Paul, MN.

b Bioreba.

${ }^{c}$ Menzel et al. 2002. J. Virol. Meth. 99:81-92.

${ }^{d}$ Di Serio et al. 2002. J. Plant Pathol. 84:27-34.

e In house developed assay.

f James et al. 2013. Arch. Virol. 158:1877-1887.

g Yoshikawa et al. 2006. Arch Virol. 151:837-848.

h Agdia.

${ }^{\text {i }}$ Foissac et al. 2005. Phytopathology 95:617-625.

j Nemchinov et al. 2000. Arch. Virol. 145:1801-1813.

k Marais et al. 2004. Acta Hortic. 657:87-92.

${ }^{1}$ Bertolini et al. 2001. J. Virol. Meth. 96:33-41.

m James et al. 2000. Arch. Virol. 145:995-1007.

${ }^{n}$ James et al. 2001. Plant Dis. 85:47-85.

o Astruc et al. 1996. Eur. J. Plant Pathol. 102:837-846.

p Vitushkina et al. 1997. Eur. J. Plant Pathol. 103:803-808.

q Rott and Jelkmann 2001. Phytopathology 91:261-297.

r James et al. 2006. Phytopathology 96:137-143.

s Hernandez et al. 1992. J. Gen. Virol. 73:2503-2507.

${ }^{t}$ Rwahnih et al. 2007. Arch. Virol. 152:2197-2206.

u Plant Print Diagnostics.

${ }^{v}$ Agritest.

${ }^{w}$ Durviz.

${ }^{x}$ Candresse et al. 1995. Acta Hortic. 386:357-369.

y Ochoa-Corona et al. 2005. Page 259 in: 15th Biennial Australasian Plant Pathology Society Conference Handbook.

z Phyto Diagnostics.

aa Griesbach 1995. Plant Dis. 79:1054-1056. 
Table 2. (continued from preceding page)

\begin{tabular}{|c|c|c|c|c|c|}
\hline \multirow[b]{2}{*}{ Virus species/disease } & \multirow[b]{2}{*}{ Host } & \multicolumn{4}{|c|}{ Test method } \\
\hline & & ELISA & PCR & Woody bioassay ${ }^{\mathbf{a}}$ & Herbaceous bioassay $^{\mathrm{a}}$ \\
\hline Cherry green ring mottle virus & Prunus & & $\mathrm{X}^{\mathrm{e}, \mathrm{i}}$ & $\begin{array}{l}\text { Kwanzan } \\
\text { P. tomentosa }\end{array}$ & \\
\hline Cherry leafroll virus & Prunus & & $\mathrm{X}^{1}$ & $\begin{array}{l}\text { GF } 305 \\
\text { Bing }\end{array}$ & $\begin{array}{l}\text { C. quinoa } \\
\text { C. amaranticolor } \\
\text { N. occidentalis } 37 B \\
\text { N. benthamiana }\end{array}$ \\
\hline Cherry mottle leaf virus & Prunus & $\mathrm{X}^{\mathrm{e}}$ & $\mathrm{X}^{\mathrm{i}, \mathrm{m}}$ & $\begin{array}{l}\text { GF } 305 \\
\text { Bing }\end{array}$ & C. quinoa \\
\hline Cherry necrotic rusty mottle virus & Prunus & & $\mathrm{X}^{\mathrm{e}, \mathrm{i}}$ & $\begin{array}{l}\text { Bing } \\
\text { Lambert } \\
\text { Sam }\end{array}$ & \\
\hline Cherry rasp leaf virus & Prunus & & $\mathrm{X}^{\mathrm{n}}$ & Bing & $\begin{array}{l}\text { C. quinoa } \\
\text { C. amaranticolor } \\
\text { N. occidentalis } 37 B \\
\text { N. benthamiana }\end{array}$ \\
\hline Cherry rusty mottle virus & Prunus & & $\mathrm{X}^{\mathrm{e}, \mathrm{i}}$ & $\begin{array}{l}\text { Bing } \\
\text { Lambert } \\
\text { Sam }\end{array}$ & \\
\hline Cherry short stem & Prunus & & & $\begin{array}{l}\text { Bing } \\
\text { Lambert }\end{array}$ & \\
\hline Cherry twisted leaf virus & Prunus & & $\mathrm{X}^{\mathrm{e}, \mathrm{i}}$ & $\begin{array}{l}\text { Bing } \\
\text { Tilton }\end{array}$ & \\
\hline Cherry virus $A$ & Prunus & & $\mathrm{X}^{\mathrm{e}}$ & & \\
\hline Flat Limb & Malus & & & Gravenstein & \\
\hline Freckle pit & Pyrus & & & Bosc & \\
\hline Hop stunt viroid & Prunus & & $\mathrm{X}^{\mathrm{o}}$ & & \\
\hline Little cherry virus- 1 & Prunus & & $\mathrm{X}^{\mathrm{p}}$ & Sam & \\
\hline Little cherry virus- 2 & Prunus & $\mathrm{X}^{\mathrm{e}}$ & $X^{\mathrm{q}}$ & $\begin{array}{l}\text { Sam } \\
\text { Tilton }\end{array}$ & \\
\hline Myrobalan latent virus & Prunus & & & GF 305 & $\begin{array}{l}\text { C. quinoa } \\
\text { C. amaranticolor } \\
\text { N. occidentalis } 37 B \\
\text { N. benthamiana }\end{array}$ \\
\hline Peach asteroid spot & Prunus & & & GF 305 & \\
\hline Peach latent mosaic viroid & Prunus & & $\mathrm{X}^{\mathrm{e}}$ & GF 305 & \\
\hline Peach mosaic virus & Prunus & & $\mathrm{X}^{\mathrm{r}}$ & GF 305 & \\
\hline Pear blister canker viroid & Pyrus & & $\mathrm{X}^{\mathrm{s}}$ & Bartlett & \\
\hline Plum bark necrosis stem pitting virus & Prunus & & $\mathrm{X}^{\mathrm{t}}$ & & \\
\hline Plum pox virus & Prunus & $\mathrm{X}^{\mathrm{u}, \mathrm{v}, \mathrm{w}}$ & $\mathrm{X}^{\mathrm{x}}$ & $\begin{array}{l}\text { GF } 305 \\
P . \text { tomentosa }\end{array}$ & N. benthamiana \\
\hline Prune dwarf virus & Prunus & $\mathrm{X}^{\mathrm{b}, \mathrm{h}}$ & & $\begin{array}{l}\text { GF } 305 \\
\text { P. tomentosa }\end{array}$ & C. sativus \\
\hline Prunus necrotic ringspot virus & Prunus & $\mathrm{X}^{\mathrm{b}}$ & & $\begin{array}{l}\text { GF } 305 \\
\text { P. tomentosa }\end{array}$ & $\begin{array}{l}\text { C. quinoa } \\
\text { C. sativus }\end{array}$ \\
\hline Raspberry ringspot virus & Malus & $\mathrm{X}^{\mathrm{b}}$ & $\mathrm{X}^{\mathrm{y}}$ & Bing & $\begin{array}{l}\text { C. amaranticolor } \\
\text { C. quinoa }\end{array}$ \\
\hline & Prunus & $\mathrm{X}^{\mathrm{b}}$ & $\mathrm{X}^{\mathrm{y}}$ & GF 305 & N. benthamiana \\
\hline Rough bark & Pyrus & & & Bartlett & \\
\hline Russet ring & Malus & & & $\begin{array}{l}\text { Spartan } \\
\text { Golden Delicious }\end{array}$ & \\
\hline Russet wart & Malus & & & $\begin{array}{l}\text { Cox's Orange Pippin } \\
\text { Golden Delicious }\end{array}$ & \\
\hline Star crack & Malus & & & $\begin{array}{l}\text { Cox's Orange Pippin } \\
\text { Golden Delicious }\end{array}$ & \\
\hline Strawberry latent ringspot virus & $\begin{array}{l}\text { Malus } \\
\text { Prunus }\end{array}$ & $\begin{array}{l}X^{b} \\
X^{b}\end{array}$ & & $\begin{array}{l}\text { Bing } \\
\text { GF } 305\end{array}$ & $\begin{array}{l}\text { C. amaranticolor } \\
\text { C. quinoa }\end{array}$ \\
\hline Stock prune & Prunus & & & GF 305 & \\
\hline Stony pit & Pyrus & & & Bosc & \\
\hline Tobacco ringspot virus & Prunus & & $\mathrm{X}^{\mathrm{e}}$ & GF 305 & $\begin{array}{l}\text { C. quinoa } \\
\text { C. amaranticolor } \\
\text { N. occidentalis } 37 B \\
\text { N. benthamiana }\end{array}$ \\
\hline Tomato blackring virus & Malus & $\mathrm{X}^{\mathrm{b}}$ & $\mathrm{X}^{\mathrm{e}}$ & GF 305 & $\begin{array}{l}\text { C. amaranticolor } \\
\text { C. quinoa }\end{array}$ \\
\hline & Prunus & $\mathrm{X}^{\mathrm{b}}$ & $\mathrm{X}^{\mathrm{e}}$ & Bing & N. benthamiana \\
\hline Tomato bushy stunt virus & Prunus & & & Bing & $\begin{array}{l}\text { C. quinoa } \\
\text { C. sativus }\end{array}$ \\
\hline Tomato ringspot virus & Malus & $\mathrm{X}^{\mathrm{h}, \mathrm{z}}$ & $\mathrm{X}^{\mathrm{aa}}$ & GF 305 & $\begin{array}{l}\text { C. amaranticolor } \\
\text { C. quinoa }\end{array}$ \\
\hline & Prunus & & $\mathrm{X}^{\mathrm{aa}}$ & P. tomentosa & $N$. benthamiana \\
\hline
\end{tabular}


multiple samples required to perform the many comparable conventional test methods, reducing material and personnel costs significantly per specimen tested. For practical diagnostic laboratory testing, this can be very significant. Extrapolating the results from the positive control specimens used in this study to samples, discrepancies can be avoided between conventional testing of multiple plant propagations, if NGS were to be used directly on the sample submitted for testing without the need for multiple propagations to be generated. Maintaining infected control material through the process of repropagation would also be greatly simplified using NGS to monitor complete virus/viroid transmission. It remains to be determined if NGS can be used to test the original source plant specimen directly as opposed to testing of plant propagations from a specimen, or if one sample point is sufficient for the detection of all viruses/ viroids. NGS does require new levels of training for diagnostic staff. NGS library construction and sequencing requires additional equipment and training, or it can be outsourced to one of many laboratories providing this service. Data interpretation is critical and workflows such as Virtool and others help to simplify this process and make it more readily available.

NGS was able to provide a more accurate species identification for 19 specimens (\#140 to \#154, \#172, \#173, \#177, and \#178). Noteworthy among these was the identification of three new virus species, a betaflexivirus related to CGRMV, CNRMV, CRMV, and ChTLV that cross reacts with these viruses by biological indexing (\#151 and \#152), a geminivirus that produced novel symptoms on an herbaceous indicator (\#158), and specimen \#153, where a novel virus was detected that has recently been characterized as Prunus virus $F$ (PrVF). In these situations, while conventional testing was unable to identify the correct virus species, a disease was detected. In a diagnostic setting, this specimen would be noted as infected and treated accordingly. In two specimens, NGS was also able to detect a novel tymovirus (\#177) and leuteovirus (\#178). These were obtained as positive controls for PPV and were not submitted for full range conventional testing. These results highlight the ability of NGS to more easily detect novel viruses. While it is possible that NGS is a better tool for the discovery of novel plant viruses, the initial detection of a novel virus-like sequence should be considered the start of further characterization studies, including transmission, host range, and pathology.

The novel viruses mentioned above can be graft transmitted to a healthy host, indicating that they are infectious agents of plants (data not shown). This is in contrast to several other viruses also detected by NGS, including toti-, birna-, and reoviruses. Totiviruses are dsRNA viruses belonging to the Totiviridae with fungi serving as natural hosts. Almost half of the 178 samples that were tested by NGS were also positive for a reovirus and or birnavirus. BLAST analysis indicates they are most closely related to insect virus species and were associated with both Malus and Prunus species. None of these viruses could be graft transmitted to a new host and are likely not plant infecting viruses (data not shown). It is likely that these viruses were detected from fungal and insect contamination of the collected leaf material. These results demonstrate not only the very high sensitivity of NGS for virus detection but also the potential pitfalls for using NGS as a diagnostic method. In particular, when a novel viral genomic sequence is detected, it is important to determine whether the virus is an infectious plant virus, a contaminant, or associated with another organism in association with the plant. While the toti-, reo-, and birnaviruses are obvious examples, an overanalysis of an NGS data set from any plant sample in this study will generate small fragments of virus-like sequences (data not shown). Most of these are presumably host plant genome contaminants. Plant RNA viruses contain conserved genes for proteins, e.g., RNA-dependent RNA polymerase, putative RNA helicase, chymotrypsin-like and/ or papain-like proteases, and methyltransferases (Koonin and Dolja 1993), which are also homologous to genes of the host plant genome. It is important not to confuse these for a plant virus by using stringent bioinformatic analysis and experimental confirmation. As mentioned, some of these sequences may be from viruses associated with the plant but are not infectious of the plant itself. This brings up a further interesting point. Infectivity of a virus is defined by its ability to move between different cells of the host. It has been demonstrated that some insect viruses can replicate within a plant cell, but are noninfectious (Selling et al. 1990). Therefore, it is possible that some of these low frequency, virus-like fragments are insect viruses that have been transferred to isolated plant cells during the course of feeding, and may be replicating in individual plant cells but are not able to move from cell to cell.

Fifty samples were infected with multiple virus species variants indicated in the comments section of Table 1. For example, in \#78, nine distinct sequence variants of ASPV could be identified and at least two ACLSV sequences. An advantage to dsRNA as a starting material for NGS is the high number of viral specific reads that can be obtained. Combined with a large number of paired-ended reads, it is easier to assemble and identify multiple sequence variants. However, in many cases it wasn't possible to identify the true number of variants, which is indicated with a " + " after the number of confirmed variants in Table 1. Several viruses, such as ASPV and ACLSV, were particularly prone to the presence of multiple variants. ASPV is a foveavirus and ACLSV is a trichovirus, both members of the Betaflexiviridae, infecting Malus. Whether these viruses are more prone to generating variants or this is an artifact of normal apple propagation practices is unclear.

The majority of plant viruses have RNA genomes (Murphy et al. 1995). Recently Basso et al. (2015) identified a group of highly divergent circular single stranded (ssDNA) viruses infecting apple, pear, and grapevine in Brazil, the first DNA viruses known to infect tree fruits. Extraction of dsRNA was chosen in this study because all known tree fruit viruses, at the start of the project, were RNA viruses, either ssRNA or dsRNA genomes. Extracts of high molecular weight dsRNA enriches for RNA viral sequences (Ralph 1969). What was unexpected was the discovery of a novel circular DNA virus in \#158 from dsRNA extracts. In studies with grapevine viruses, we have been able to detect Grapevine red blotch virus, also a circular DNA virus, from dsRNA extracts (publication submitted). It is possible that circular DNA viruses with ambisense genomes that express RNA transcripts from both strands are unique and produce genomic length dsRNA by-products that are detectable using the methods described here. However, other studies have also found DNA viruses associated with dsRNA (Son et al. 2015). More work is required to determine whether dsRNA extractions can be universally applied for RNA and DNA viruses infecting plants.

In summary, NGS is a viable method for the detection and identification of virus and virus-like agents infecting tree fruits with advantages over conventional testing and some limitations. As a method, NGS cannot compare with PCR or ELISA where the goal is the detection of one or a few specific viruses, such as surveying for Plum pox virus (Thompson et al. 2001). NGS is most useful as a screening method for a large number of viruses and/or where there is a need to identify a novel causal agent of a disease with virus-like symptoms, or simply a need to identify all viruses that may be present as is the case for national and international certified import/export programs and breeding programs. The potential reduction in cost and time for these activities is considerable and it is only a matter of time before NGS becomes an integral method with the potential of replacing the bioassay. For research, the ability for new virus discovery and to better characterize the variability of viral sequences in an infected plant are unprecedented (Adams et al. 2009; Al Rwahnih et al. 2015; Barba et al. 2014; Barzon et al. 2011; Candresse et al. 2014; Coetzee et al. 2010; Kreuze et al. 2009; Martin et al. 2016; Massart et al. 2014; Mokili et al. 2012; Roossinck et al. 2010). Caution, however, needs to be exercised and NGS should be used in conjunction with a confirmatory method. The high sensitivity of NGS to detect very low virus concentrations also makes it highly sensitive to cross contamination of samples, or samples contaminated with mycoviruses, insect viruses, or others. It is important to not overanalyze the NGS data but to develop effective workflows to handle the large data sets to efficiently detect viruses of interest and eliminate spurious results. 


\section{Acknowledgments}

We would like to thank Dr. Thomas Niederberger and Allison Gratz for critical review of this manuscript. This work was funded through the Government of Canada, Genomics Research and Development Initiative: Protection of Canadian biodiversity and trade from the impacts of global change through improved ability to monitor invasive alien and quarantine species.

\section{Literature Cited}

Adams, I. P., Glover, R. H., Monger, W. A., Mumford, R., Jackeviciene, E., Navalinskiene, M., Samuitiene, M., and Boonham, N. 2009. Next-generation sequencing and metagenomic analysis: a universal diagnostic tool in plant virology. Mol. Plant Pathol. 10:537-545.

Al Rwahnih, M., Daubert, S., Golino, D., Islas, C., and Rowhani, A. 2015. Comparison of next-generation sequencing versus biological indexing for the optimal detection of viral pathogens in grapevine. Phytopathology 105: 758-763.

Bankevich, A., Nurk, S., Antipov, D., Gurevich, A. A., Dvorkin, M., Kulikov, A. S., Lesin, V. M., Nikolenko, S. I., Pham, S., Prjibelski, A. D., Pyshkin, A. V., Sirotkin, A. V., Vyahhi, N., Tesler, G., Alekseyev, M. A., and Pevzner, P. A. 2012. SPAdes: a new genome assembly algorithm and its applications to single-cell sequencing. J. Comput. Biol. 19:455-477.

Barba, M., Czosnek, H., and Hadidi, A. 2014. Historical perspective, development and applications of next-generation sequencing in plant virology. Viruses 6 : 106-136.

Barzon, L., Lavezzo, E., Militello, V., Toppo, S., and Palu, G. 2011. Applications of next-generation sequencing technologies to diagnostic virology. Int. J. Mol. Sci. 12:7861-7884.

Basso, M. F., da Silva, J. C., Fajardo, T. V., Fontes, E. P., and Zerbini, F. M. 2015. A novel, highly divergent ssDNA virus identified in Brazil infecting apple, pear and grapevine. Virus Res. 210:27-33.

Candresse, T., Filloux, D., Muhire, B., Julian, C., Galzi, S., Fort, G., Bernardo, P., Daugrois, J. H., Fernandez, E., Martin, D. P., Varsani, A., and Roumagnac, P. 2014. Appearances can be deceptive: revealing a hidden viral infection with deep sequencing in a plant quarantine context. PLoS One 9:e102945.

Coetzee, B., Freeborough, M. J., Maree, H. J., Celton, J. M., Rees, D. J., and Burger, J. T. 2010. Deep sequencing analysis of viruses infecting grapevines: Virome of a vineyard. Virology 400:157-163.

Eddy, S. R. 2011. Accelerated profile HMM searches. PLOS Comput. Biol. 7: e1002195.

Foissac, X., Svanella-Dumas, L., Gentit, P., Dulucq, M. J., Marais, A., and Candresse, T. 2005. Polyvalent degenerate oligonucleotides reverse transcriptionpolymerase chain reaction: a polyvalent detection and characterization tool for trichoviruses, capilloviruses, and foveaviruses. Phytopathology 95 : 617-625.

Hadidi, A., Levy, L., and Podleckis, E. V. 1995. Polymerase chain reaction technology in plant pathology. Pages 167-187 in: Molecular Methods in Plant Pathology. R. P. Sigh and U. S. Sigh, eds. CRC Press, Boca Raton, FL.

Hari, V., and Das, P. 1998. Ultramicrosopic detection of plant viruses and their gene products. Pages 417-427 in: Plant Viruses Disease Control. A. Hadidi, R. K. Khetarpal, and H. Kogenizawa, eds. APS Press, St Paul, MN.

Ho, T., and Tzanetakis, I. E. 2014. Development of a virus detection and discovery pipeline using next generation sequencing. Virology 471-473:54-60.

Hong, C., Manimaran, S., Shen, Y., Perez-Rogers, J. F., Byrd, A. L., Castro-Nallar, E., Crandall, K. A., and Johnson, W. E. 2014. PathoScope 2.0: a complete computational framework for strain identification in environmental or clinical sequencing samples. Microbiome 2:33.

Jiang, H., Lei, R., Ding, S. W., and Zhu, S. 2014. Skewer: a fast and accurate adapter trimmer for next-generation sequencing paired-end reads. BMC Bioinformatics 15:182.

Jones, R. A. 2014. Trends in plant virus epidemiology: opportunities from new or improved technologies. Virus Res. 186:3-19.

Kesanakurti, P., Belton, M., Saeed, H., Rast, H., Boyes, I., and Rott, M. 2016. Screening for plant viruses by next generation sequencing using a modified double strand RNA extraction protocol with an internal amplification control. J. Virol. Methods 236:35-40.

Koonin, E. V., and Dolja, V. V. 1993. Evolution and taxonomy of positive-strand RNA viruses: implications of comparative analysis of amino acid sequences. Crit. Rev. Biochem. Mol. Biol. 28:375-430.

Kreuze, J. F., Perez, A., Untiveros, M., Quispe, D., Fuentes, S., Barker, I., and Simon, R. 2009. Complete viral genome sequence and discovery of novel viruses by deep sequencing of small RNAs: a generic method for diagnosis, discovery and sequencing of viruses. Virology 388:1-7.

López, M. M., Bertolini, E., Marcos-Noales, E., Llop, P., and Cambra, M. 2006. Update on molecular tools for detection of plant pathogenic bacteria and viruses. Pages 1-46 in: Molecular diagnostics: Current Technology and Applications. J. R. Rao, C. C. Fleming, and J. E. Moore, eds. Horizon Scientific Press, Hethersett, U.K.

Langmead, B., and Salzberg, S. L. 2012. Fast gapped-read alignment with Bowtie 2. Nat. Methods 9:357-359.

Martin, R. R., Constable, F., and Tzanetakis, I. E. 2016. Quarantine regulations and the impact of modern detection methods. Annu. Rev. Phytopathol. 54:189-205.

Massart, S., Olmos, A., Jijakli, H., and Candresse, T. 2014. Current impact and future directions of high throughput sequencing in plant virus diagnostics. Virus Res. 188:90-96.

Mokili, J. L., Rohwer, F., and Dutilh, B. E. 2012. Metagenomics and future perspectives in virus discovery. Curr. Opin. Virol. 2:63-77.

Murphy, F. A., Fauquet, C. M., Bishop, D. H. L., Ghabril, S. A., Jarvis, A. W., Martelli, G. P., Mayo, M. A., and Summers, M. D. 1995. Virus taxonomy: classification and nomenclature of viruses. Arch. Virol. Suppl. 10:10.

Ralph, R. K. 1969. Double-stranded viral RNA. Adv. Virus Res. 15:61-158.

Roossinck, M. J. 2010. Lifestyles of plant viruses. Philos. Trans. R. Soc. Lond. B Biol. Sci. 365:1899-1905.

Roossinck, M. J. 2012. Plant virus metagenomics: biodiversity and ecology. Annu. Rev. Genet. 46:359-369.

Roossinck, M. J., Saha, P., Wiley, G. B., Quan, J., White, J. D., Lai, H., Chavarria, F., Shen, G., and Roe, B. A. 2010. Ecogenomics: using massively parallel pyrosequencing to understand virus ecology. Mol. Ecol. 19 (Suppl 1):81-88.

Selling, B. H., Allison, R. F., and Kaesberg, P. 1990. Genomic RNA of an insect virus directs synthesis of infectious virions in plants. Proc. Natl. Acad. Sci. USA 87:434-438.

Skewes-Cox, P., Sharpton, T. J., Pollard, K. S., and DeRisi, J. L. 2014. Profile hidden Markov models for the detection of viruses within metagenomic sequence data. PLoS One 9:e105067.

Son, K. N., Liang, Z., and Lipton, H. L. 2015. Double-stranded RNA is detected by immunofluorescence analysis in RNA and DNA virus infections, including those by negative-stranded RNA viruses. J. Virol. 89:9383-9392.

Thompson, D., Howell, W. E., and Kolber, M. 2011. Biological Indexing. Pages 299-302 in: Viruses and Virus-like Diseases of Pome and Stone Fruits. A Hadidi, M. Barba, T. Candresse, and W. Jelkmann, eds. APS Press, MN.

Thompson, D., McCann, M., MaCleod, M., Lye, D., Green, M., and James, D. 2001. First report of Plum pox potyvirus in Ontario, Canada. Plant Dis. 85:97.

Villamor, D. E., Mekuria, T. A., Pillai, S. S., and Eastwell, K. C. 2016. Highthroughput sequencing identifies novel viruses in nectarine: insights to the etiology of stem-pitting disease. Phytopathology 106:519-527.

Villamor, D. E., Susaimuthu, J., and Eastwell, K. C. 2015. Genomic analyses of cherry rusty mottle group and cherry twisted leaf-associated viruses reveal a possible new genus within the family betaflexiviridae. Phytopathology 105: 399-408.

Villamor, D. E. V., Pillai, S. S., and Eastwell, K. C. 2017. High throughput sequencing reveals a novel fabavirus infecting sweet cherry. Arch. Virol. 162:811-816.

Visser, M., Bester, R., Burger, J. T., and Maree, H. J. 2016. Next-generation sequencing for virus detection: covering all the bases. Virol. J. 13:85.

Zheng, Y., Gao, S., Padmanabhan, C., Li, R., Galvez, M., Gutierrez, D., Fuentes, S., Ling, K. S., Kreuze, J., and Fei, Z. 2017. VirusDetect: An automated pipeline for efficient virus discovery using deep sequencing of small RNAs. Virology 500:130-138. 